\section{DEVELOPMENT OF CRASH MODIFICATION FACTORS FOR CONTINUOUS FLOW INTERSECTIONS}

\author{
Milan Zlatkovic, Ph.D., P.E., mzlatkov@uwyo.edu \\ University of Wyoming, Laramie, Wyoming, USA
}

Cameron Kergaye, Ph.D., P.E., ckergaye@utah.gov

Utah Department of Transportation, Salt Lake City, Utah, USA

DOI: 10.31075/PIS.64.03.01

Professional paper

Abstract: Innovative intersections are defined as any at-grade design concepts that are able to reduce the number of signal phases at the main intersection. The Continuous Flow Intersection (CFI) displaces the left turns from the main intersection approach using an additional upstream crossover, allowing the left turns to run concurrently with the through movements. This improves operations and increases the intersection capacity. It also benefits safety by reducing the number of conflict points. This paper presents a safety analysis and the development of Crash Modification Factors (CMF) for CFls using the Empirical Bayes (EB) methodology. The methodology is applied to before and after crash data for eight treatment sites (conversion to $\mathrm{CFI}$ ) and five sites in the comparison group. The results show that partial CFIs experience about $12 \%$ less total crashes after conversion. Further analysis needs to be conducted for different crash types and crash severity.

Keywords: Crash Modification Factors, Continuous Flow Intersection, Safety Performance, Empirical Bayes

\section{INTRODUCTION}

Innovative (unconventional, alternative) intersections are generally defined as design concepts that are able to reduce the number of signal phases, thereby improving the overall operational and safety performance [1]. In most cases this is accomplished by rerouting left turns at a point well ahead of the main intersection, or accomplishing left turns through a combination of through, right and U-turn movements. These designs are regarded to be "unconventional" because they incorporate geometric features or movement restrictions that would be permissible for standard designs [2]. Such elements include the elimination or relocation of various through and turning maneuvers, the use of indirect turning movements, and the inclusion of roundabout designs.

The general goal of innovative designs is to improve operations by favoring heavy volume through movements, to decrease crash frequencies or severities through geometric designs which encourage conflict avoidance, and to provide design alternatives that accommodate travel demand without the need to fund major construction work. One of the recognized problems with new implementations of innovative designs is the issue of driver expectancy. As drivers are used to conventional designs, maneuvering might be challenging due to rerouted movements. The Continuous Flow Intersection (CFI) is an innovative design that displaces the left turns from the main intersection approach using an additional upstream crossover, allowing the left turns to run concurrently with the through movements. A CFI can be full or partial, depending on the number of displaced left turns, and can be applied to three of four legged intersections. A significant number of CFI conversions in the State of Utah over the past several years made Utah a leader in the US in implementation of these designs. A CFI can increase the intersection capacity close to $50 \%$ compared to a four-legged intersection [1, 2], due to the additional green time and higher saturation flow rates. It also reduces the number of conflict points, therefore having the potential to improve safety. However, concrete safety benefits for CFI conversion are still not well documented.

A crash modification factor (CMF) is a multiplicative factor used to compute the expected number of crashes after implementing a given countermeasure at a specific site $[4,5]$. It is the ratio of the effectiveness of one condition in comparison to another condition. CMFs are multiplied with the crash frequency predicted by the SPF to account for the difference between site conditions and specified base conditions. There are different methodologies for CMF calculation. In most cases it is developed through a type of before-after safety study. Currently, the most commonly used and recommended method is the Empirical Bayes (EB) method. It combines an estimation of the study site crash frequency with characteristics of similar sites using Safety Performance Functions (SPFs) to estimate the predicted number of crashes [5 - 7].

This paper presents a development of CMFs for the four-legged CFI conversion for Utah conditions. The developed CMFs are valid for partial CFIs, where the displaced left turns exist only on two approaches. It uses a treatment group that consists of eight intersections converted to CFls (seven partial and one full), and a comparison group of five comparable four-legged signalized intersections. Presently, there are no CMFs for CFI conversion in the published literature, mainly because of the limited number of implementations and the lack of data for the after period. This paper presents a preliminary analysis using two to three years of crash data for the after period (the implementation year is not included in the EB models) at the eight analyzed sites. 
The paper is organized in six sections. The following section presents an overview of CFIs. It is followed by two sections that describe intersection SPFs and the EB method. The next section provides the analysis of crash data and CMF development for the selected Utah CFI sites. The major conclusions of the paper are given in the last section.

\section{CFI OVERVIEW}

The CFI is a complex unconventional intersection design in terms of lane configurations, channelizing and control features. The basic concept of the CFI is to move the left turn traffic from all approaches of the main intersection across the opposing traffic lanes prior to the main intersection [1,2, 8]. Left turn maneuvers are then completed simultaneously and unopposed with their accompanying and opposing through movements, allowing the intersection to operate on a two-phase signal. For comparison, a standard signal with protected left turn arrows must serve eight major movements, four left turns and four through movements, but only two movements can occur at a time, which demands a four-phase signal. The left turns prior to the intersection are also signalized, but they are coordinated with the main signal allowing the left turning vehicles to cross the main intersection without stopping. The diagram of a $\mathrm{CFI}$ intersection is given in Figure 1. It shows only the CFI design on the major roadway (partial CFI), although it can be implemented on all approaches.

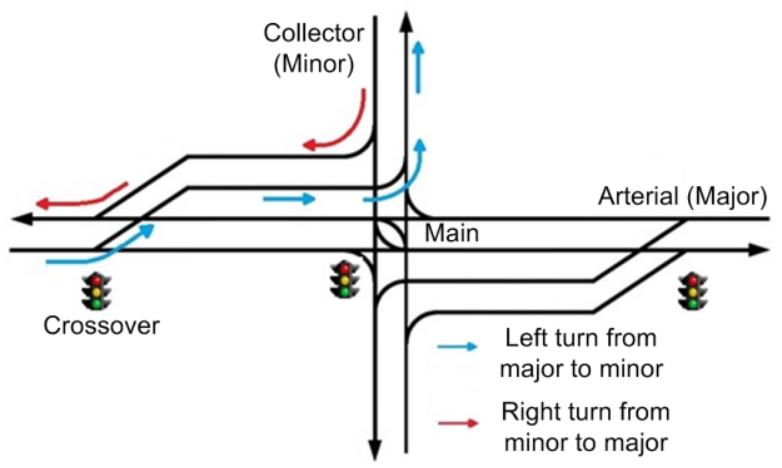

Figure 1: Partial Continuous Flow Intersection (CFI)

A full 4-approach CFI with 2-3 lanes per approach can handle about 10,000 - 14,000 vehicles per hour at the Level of Service (LOS) E. A standard intersection with the same number of through lanes and with dual leftturn lanes on all approaches can handle about 6,000 8,000 vehicles per hour at the same LOS. The CFI design can greatly increase capacity and reduce delays $[1,2,8]$. It is most effective in reducing travel times when the left turn volumes are high [9]. The specific design of the CFI increases the complexity of the signal control program. It needs to include additional phases and introduce overlap phasing, with a special attention given to the coordination of left turns and pedestrian phasing [10 - 12].
The CFI design can also impede public transit operations. However, studies have shown that the design and operations can be optimized if transit is present, including preferential treatments, so that any impacts on transit are minimal or nonexistent $[13,14]$. Currently, little is documented about the safety performance of CFIs, mostly due to the fact that there are limited data for the after implementation period [8]. The CMF Clearinghouse does not provide any data on CFI conversion [4]. Because of their design, CFIs offer several potential safety advantages compared to the conventional intersection by reducing conflict points and channelizing turning movements. The number of vehicle-to-vehicle conflict points for a conventional four-legged intersection is 32 (16 crossing, 8 merging and 8 diverging). For a full $\mathrm{CFI}$, this number is 28 ( 12 crossing, 8 merging and 8 diverging), or 30 for a partial CFI. Conflict points for a conventional intersection and a full $\mathrm{CFI}$ are shown in Figure 2.

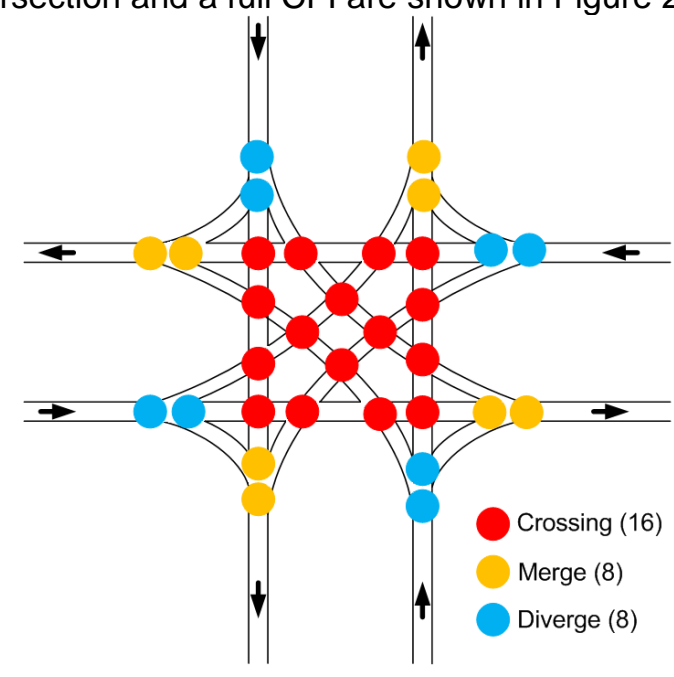

a)

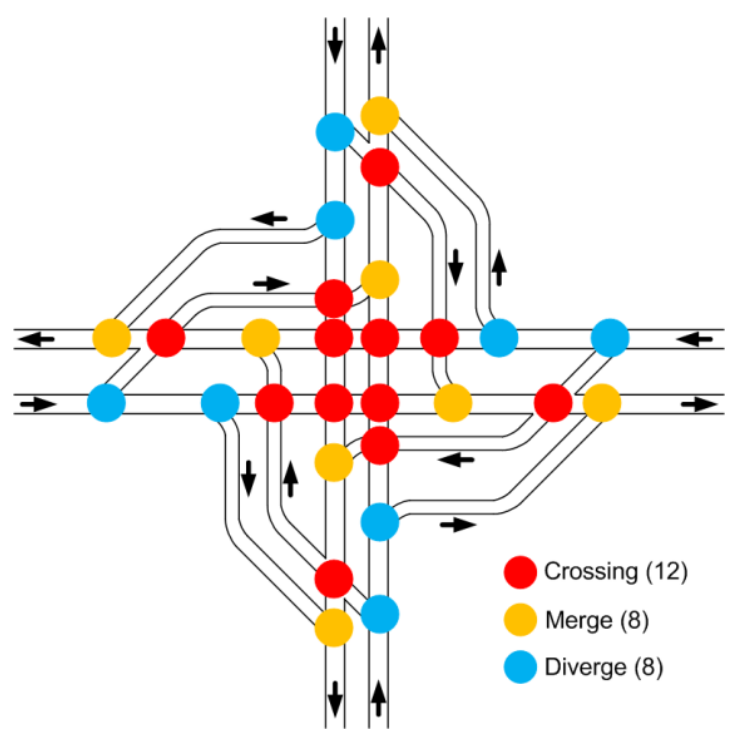

b)

Figure 2: Vehicle-to-Vehicle Conflict Points a) Conventional Intersection; b) Full CFI 
The main safety advantage comes from the reduction in the number of crossing conflict points, since these types of crashes result in higher severity. Vehicle-to-vehicle conflicts are correlated with collisions, therefore they are often used as surrogate measures to compare different intersection forms [8]. However, this approach cannot be used for three-legged intersections, since the number of conflict points is the same for conventional and CFI designs.

The design of the CFI, particularly the displaced left turns, are counterintuitive to the drivers unfamiliar with its operation. This can cause errors in drivers' judgements and maneuvers, leading to potential safety issues $[1-3,8,15]$. A study using video recordings of two CFIs (one in Utah and one in Louisiana) found that more than $90 \%$ of drivers' errors included improper lane change, diverge and red light violations during the first year after the implementation [15]. These numbers reduced significantly afterwards when the drivers became familiar with CFI operations. Other dangerous maneuvers, such as U-turns at the crossovers or improper left turns at the main intersection were also recorded, however they had relatively low frequencies.

To resolve some of these issues, clear guidance must be given to the drivers to warn them of the lane separation and guide them into the appropriate lanes, especially the left turning vehicles. Because of the multiple lane crossings within the intersection, pedestrians also need to be guided and informed. There is also a need for U-turn opportunities in the vicinity of the CFI, because access to and egress from intersections quadrant developments are difficult for most approach movements. The CFI would be most appropriate for high volume arterials with heavy left turns, and with few needs for U-turns. Another important consideration is the level of development near the intersection. Because of the locations of the left and right turn lanes, the CFI does not provide easy access to and from adjacent properties.

\section{INTERSECTION SAFETY PERFORMANCE FUNCTIONS}

A crucial element in the EB analysis method is predicting the number of crashes for the treatment and comparison sites by applying appropriate SPFs. SPFs are statistical regression models used to estimate the average crash frequency for a facility type with specified base conditions, and they are part of the predictive methods [5]. They are developed for sets of observed crash data for different facilities, and they estimate the value of a dependent variable (crash frequency) as a function of a set of independent variables (geometry, traffic, control, environmental conditions and similar). A
CMF is the ratio of the effectiveness of one condition in comparison to another condition. CMFs are multiplied with the crash frequency predicted by the SPF to account for the difference between site conditions and specified base conditions [4, 5]. The Highway Safety Manual (HSM) [5] provides a synthesis of methodologies for the development of SPFs and CMFs for different facilities. Chapter 12 describes the predictive methodology for analyzing crashes at signalized intersections. This methodology contains SPFs and CMFs for different geometrical and operational characteristics of signalized intersections. The effect of traffic volumes on major and minor intersection approaches on predicted crash frequency is incorporated through the SPFs, while the effects of geometric and traffic control features are incorporated through available CMFs. The SPFs address four types of crashes: multiple-vehicle, single-vehicle, vehicle-pedestrian and vehicle-bicycle crashes.

The signalized intersection SPF for total multiplevehicle crashes has the following form:

$\mathrm{N}_{\text {bimv }}=\exp \left(\mathrm{a}+\mathrm{b} \cdot \ln \left(\operatorname{AADT}_{\mathrm{maj}}\right)+\mathrm{c} \cdot \ln \left(\mathrm{AADT}_{\min }\right)\right)$

(1)

Where:

$N_{\text {bimv }}$ - predicted crash frequency for total multiple-vehicle crashes (crashes/yr)

$\mathrm{AADT}_{\text {maj }}$ - AADT on the major intersection approach (veh/day)

$\mathrm{AADT}_{\text {min }}$ - AADT on the minor intersection approach (veh/day)

a, b, c - regression coefficients

The SPF for single-vehicle crashes $\mathrm{N}_{\text {bisv }}$ has the same form, only with different regression coefficients. The regression coefficients depend on the intersection type (three or four-legged) and are given separately total, fatal and injury and propertydamage only crashes. The HSM also provides SPFs for vehicle-pedestrian and vehicle-bicycle collisions. However, pedestrian and bicycle volumes at intersections in most cases are not available. For that reason it is usually assumed that vehiclepedestrian and vehicle-bicycle crashes combined ( $\mathrm{Nbi}_{\text {(ped/bike) }}$ are approximately $4 \%$ of the multiplevehicle crashes.

The available CMFs for signalized intersections include CMF for exclusive left turn lanes (CMFLT), CMF for exclusive right turn lanes $\left(\mathrm{CMF}_{\mathrm{RT}}\right)$, and

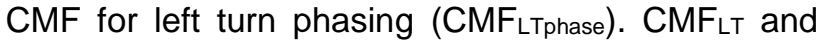
$\mathrm{CMF}_{\mathrm{RT}}$ are determined based on the intersection type (three or four-legged) and the number of approaches with left and right turn lanes. CMF $F_{\text {TTphase }}$ is determined separately for protected, permitted or protected/permitted left turn signal phasing for each intersection approach separately, and then the 
obtained values are multiplied to determine CMFLTphase for the entire intersection. For local conditions, it is assumed that intersection lighting exists $\left(\mathrm{CMF}_{\text {light }}=0.91\right)$ and that there are no redlight cameras $\left(\mathrm{CMF}_{\mathrm{rl}} \mathrm{cam}=1.0\right)$. These $\mathrm{CMFs}$ are provided in the HSM. The combined $\mathrm{CMF}_{\text {comb }}$ therefore can be computed as:

$\mathrm{CMF}_{\text {comb }}=\mathrm{CMF}_{\mathrm{LT}} \cdot \mathrm{CMF}_{\mathrm{RT}} \cdot \mathrm{CMF}_{\mathrm{LTphase}}$

The number of predicted crashes for an entire intersection can then be determined as:

$\mathrm{N}_{\text {pred }}=\mathrm{CMF}_{\text {comb }} \cdot\left(\mathrm{N}_{\text {bimv }}+\mathrm{N}_{\text {bisv }}+\mathrm{N}_{\text {bi(ped/bike })}\right)$

\section{EMPIRICAL BAYES METHOD}

The EB method is a procedure for statistical inference in which the prior distribution is estimated from the data. It combines an estimation of the study site crash frequency (treatment group) with characteristics of similar sites (comparison group) using SPFs to estimate the predicted number of crashes [6,7]. It is shown that the EB method is better suited to estimate safety than the more traditional statistical methods. The EB methodology presented here is adapted from [16]. Major characteristics of the EB method are as follows:

- It accounts, directly with modeling, for changes in factors that are measured and understood

- It accounts for changes in unmeasured factors

- It accounts for "regression-to-the-mean" bias: the "before" crash counts alone may not be a good basis for predicting "what would have been"

The main parameters used in the presented analysis are as follows:

a) "before" period: from the start year of analysis until the year before the treatment was implemented

b) "after" period: from one year after the treatment was implemented until the end year of analysis

c) $\hat{\pi}$ - predicted number of crashes in the "after" period: what would have been if the treatment had not been implemented, all sites

$\widehat{\pi}_{\mathrm{j}}=\mathrm{C}_{\mathrm{j}} \cdot \mathrm{M}_{\mathrm{j}}$

where:

$j-$ site code

$$
\mathrm{C}_{\mathrm{j}}=\frac{\sum \text { pred.crashes in after period for site } \mathrm{j}}{\sum \text { pred.crashes in before period for site } \mathrm{j}}
$$

$$
\mathrm{M}_{\mathrm{j}}=\mathrm{w}^{*} \mathrm{P}_{\mathrm{j}}+(1-\mathrm{w}) \cdot \mathrm{K}_{\mathrm{j}}
$$

with the following:

$$
\text { w - weight, computed as }
$$

$$
w=\frac{1}{1+k \cdot P_{j}}
$$

$\mathrm{k}$ - overdispersion parameter, which was calculated when SPFs were developed, and is provided in the HSM

$\mathrm{K}_{\mathrm{j}}=\sum$ obs.crashes in before period for site $\mathrm{j}$

$P_{j}=\sum$ pred. crashes in before period for site $j$

$\widehat{\pi}=\sum_{j} \widehat{\pi}_{j}$

d) $\operatorname{VAR}\left\{\widehat{\pi}_{\mathrm{j}}\right\}=\mathrm{C}_{\mathrm{j}}^{2} \cdot \operatorname{VAR}\left\{\mathrm{M}_{\mathrm{j}}\right\}$

where:

$$
\begin{aligned}
& \operatorname{VAR}\left\{M_{j}\right\}=M_{j} *(1-w) \\
& \operatorname{VAR}\{\widehat{\pi}\}=\sum_{j} \operatorname{VAR}\left\{\widehat{\pi}_{j}\right\}
\end{aligned}
$$

e) $\hat{\lambda}$ - observed number of crashes in the "after" period: what actually was after the treatment had been implemented, all sites

$\hat{\lambda}_{j}=\sum$ obs. crashes in after period for site $j$

$$
\widehat{\lambda}=\sum_{\mathrm{j}} \hat{\lambda}_{\mathrm{j}}
$$

f) $\operatorname{VAR}\left\{\hat{\lambda}_{j}\right\}=\hat{\lambda}_{j}$

$$
\operatorname{VAR}\{\hat{\lambda}\}=\sum_{j} \operatorname{VAR}\left\{\hat{\lambda}_{j}\right\}
$$

g) $\theta$ - the ratio of the observed number of crashes in the after period with the treatment, to the predicted number of crashes in the after period if the treatment had not been implemented, applied to all treated sites, computed as:

$$
\hat{\theta}=\frac{\bar{\lambda}}{\hat{\pi}\left(1+{ }^{\operatorname{VAR}[\tilde{\pi}]} / \widehat{\pi}^{2}\right)}
$$


$\operatorname{VAR}\{\hat{\theta}\}=\hat{\theta}^{2} \cdot \frac{1 / \widehat{\lambda}^{+} \operatorname{VAR}\{\tilde{\pi}\} / \widehat{\pi}^{2}}{\left(1+{ }^{\operatorname{VAR}\{\tilde{\pi}\}} / \widehat{\pi}^{2}\right)^{2}}$

$\theta$ actually represents the CMF for the applied treatment.

h) $\sigma\{\hat{\theta}\}=\sqrt{\operatorname{VAR}\{\hat{\theta}\}}$

standard deviation of $\ddot{\theta}$

i) $\delta=\widehat{\pi}-\hat{\lambda}$

the reduction in number of crashes in the after period (what would have been minus what actually was)

$$
\text { j) } \operatorname{VAR}\{\delta\}=\operatorname{VAR}\{\widehat{\pi}\}+\operatorname{VAR}\{\lambda\}
$$

The described EB methodology was applied to the CFI treated sites and comparison sites, using the crash data for the period 2008 - 2013, as described in the following section.

\section{DEVELOPMENT OF CRASH MODIFICATION FACTORS}

The crash data for the analysis were obtained from the Utah Department of Transportation (UDOT) Traffic and Safety Division, the Average Annual Daily Traffic (AADT) data through the UDOT Open Data portal, and the intersection geometry and signal phasing was recorded through Google Earth and site visits. The crash data contains the exact location (lat/long coordinates) for each crash, and this piece of information was used to filter out all crashes that happened in the vicinity of the intersection, for each of the six years. Since the provided intersection SPFs only capture intersection-related crashes, the intersection influence area was defined as the radius of $76 \mathrm{~m}$ $(250 \mathrm{ft})$ from the center of the intersection (which is generally the distance where the turn lanes begin). Using the exact coordinates of each intersection, their influence areas and the crash coordinates, a search application was developed to count the number of crashes for each intersection.

The comparison group contains of five signalized intersections with traffic volumes comparable to the sites that were converted to CFIs. Crash data for these sites are given in Table 1. The AADT data for major and minor approaches were also collected and used in analysis, but could not be shown here due to space constraints. These sites were also used to develop the local calibration factor for Utah conditions, CUT. The predicted number of crashes was calculated after calibration, and the results are presented in Table 2.
The treatment group contains of eight sites which were converted from four-legged intersections into CFIs. Only one intersection is a full CFI (Bangerter and $4700 \mathrm{~S}$ ), while all others are partial CFls with displaced left turns on two approaches. The observed crash data for these sites are given in Table 3, while the predicted number of crashes is shown in Table 4. These results were used as inputs for the EB analysis.

Table 1: Observed Signalized Intersection Crash Data (Comparison Sites)

\begin{tabular}{|c|c|c|c|c|c|c|}
\hline \multirow{2}{*}{} & \multicolumn{6}{|c|}{ Total Observed Crashes per Year } \\
\cline { 2 - 7 } & 2008 & 2009 & 2010 & 2011 & 2012 & 2013 \\
\hline $\begin{array}{c}\mathrm{RR} / 35^{\text {th }} \\
\mathrm{S}\end{array}$ & 41 & 48 & 30 & 45 & 46 & 59 \\
\hline $\begin{array}{c}56^{\text {th }} \mathrm{W} / \\
35^{\text {th }} \mathrm{S}\end{array}$ & 57 & 43 & 44 & 38 & 77 & 57 \\
\hline $\begin{array}{c}\text { State } / \\
45^{\text {th }} \mathrm{S}\end{array}$ & 47 & 38 & 35 & 42 & 46 & 94 \\
\hline $\begin{array}{c}\text { State } / \\
33^{\text {rd }} \mathrm{S}\end{array}$ & 44 & 39 & 40 & 53 & 43 & 34 \\
\hline $\begin{array}{c}7^{\text {th }} \mathrm{E} / \\
3^{\text {rd }} \mathrm{S}\end{array}$ & 30 & 36 & 25 & 60 & 35 & 43 \\
\hline
\end{tabular}

RR - Redwood Road

Using equations (1) and (2), intersection geometries and AADT and crash data, the predicted number of crashes was computed for each site and year, and compared to the observed data. Based on that, the local calibration factor was determined as follows:

$C_{U T}=\frac{\sum_{2008}^{2013} N_{\text {total observed }}}{\sum_{2008}^{2013} N_{\text {total }} \text { predicted }}=4.52$

Finally, the calibrated predicted number of crashes for each comparison site and year was calculated, as given in Table 2. The yearly modification factor, $a_{y}$, was calculated using the observed and predicted number of crashes and is given in the last row. These results were also used later in the EB methodology.

Table 2: Predicted Signalized Intersection Crash Data (Comparison Sites)

\begin{tabular}{|c|c|c|c|c|c|c|}
\hline & \multicolumn{6}{|c|}{ Total Predicted Crashes per Year } \\
\hline & 2008 & 2009 & 2010 & 2011 & 2012 & 2013 \\
\hline $\begin{array}{c}\mathrm{RR} / 35^{\text {th }} \\
\mathrm{S}\end{array}$ & 35.3 & 35.0 & 35.3 & 35.3 & 34.5 & 26.1 \\
\hline $\begin{array}{c}56^{\text {th }} \mathrm{W} / \\
35^{\text {th }} \mathrm{S}\end{array}$ & 33.3 & 33.6 & 33.6 & 35.2 & 35.1 & 36.3 \\
\hline $\begin{array}{l}\text { State / } \\
45^{\text {th } ~} S\end{array}$ & 29.0 & 29.2 & 29.2 & 35.4 & 35.1 & 35.9 \\
\hline $\begin{array}{l}\text { State I } \\
33^{\text {rd }} \mathrm{S}\end{array}$ & 30.8 & 30.9 & 30.9 & 29.4 & 29.2 & 29.9 \\
\hline $\begin{array}{l}7^{\text {th }} \mathrm{E} / \\
33^{\text {rd }} S\end{array}$ & 36.8 & 36.0 & 34.8 & 34.4 & 32.8 & 32.9 \\
\hline$a_{y}$ & 1.03 & 0.91 & 0.76 & 1.08 & 1.09 & 1.12 \\
\hline
\end{tabular}


The observed crash data for the eight treatment sites is given in Table 3. CFls were installed in 2010 or 2011, as shown in the table. The year of installation was not included in the "after" period, as defined in the EB parameters. The predicted number of total crashes for the treatment sites (including both before and after periods) can be obtained as follows:

$\mathrm{N}_{\text {pred }}=\mathrm{a}_{\mathrm{y}} \cdot \mathrm{C}_{\mathrm{UT}} \cdot \mathrm{CMF}_{\text {comb }} \cdot\left(\mathrm{N}_{\text {bimv }}+\mathrm{N}_{\text {bisv }}+\right.$

$\mathrm{N}_{\text {bi(ped/bike) })}$

This predicted number of crashes for the treatment sites represents a starting point in the Empirical Bayes (EB) analysis. Note that this result does not include the CMF for CFI conversion, which is to be determined based on these data. The results for total predicted crashes for these sites are given in Table 4.

Table 3: Observed Signalized Intersection Crash Data (Treatment Sites)

\begin{tabular}{|c|c|c|c|c|c|c|}
\hline & \multicolumn{6}{|c|}{ Total Observed Crashes per Year } \\
\hline & 2008 & 2009 & 2010 & 2011 & 2012 & 2013 \\
\hline Bgr. / 31st S & 23 & 31 & 11 & $26^{*}$ & $18^{*}$ & $23^{*}$ \\
\hline Bgr. / 41, S & 49 & 51 & 34 & $47^{*}$ & $57^{*}$ & $63^{*}$ \\
\hline Bgr. $/ 47^{\text {th }} S^{1}$ & 66 & 62 & $48^{*}$ & $47^{*}$ & $47^{*}$ & $63^{*}$ \\
\hline Bgr. $/ 54^{\text {th }} \mathrm{S}$ & 108 & 70 & $109^{*}$ & $91^{*}$ & $95^{*}$ & $96^{*}$ \\
\hline Bgr. $/ 62^{\text {nd }} S$ & 46 & 57 & 47 & $82^{*}$ & $102^{*}$ & $94^{*}$ \\
\hline Bgr. $/ 70^{\text {th }} \mathrm{S}$ & 36 & 43 & 33 & $39^{*}$ & $42^{*}$ & $57^{*}$ \\
\hline $\mathrm{RR} / 54^{\text {th }} \mathrm{S}$ & 66 & 73 & $68^{*}$ & $75^{*}$ & $64^{*}$ & $53^{*}$ \\
\hline $\mathrm{RR} / 62^{\text {nd }} \mathrm{S}$ & 74 & 70 & $85^{*}$ & $47^{*}$ & $79^{*}$ & $44^{*}$ \\
\hline
\end{tabular}

Bgr. - Bangerter Highway; RR - Redwood Road ${ }^{*} \mathrm{CFI}, 1$ Full CFI

Table 4: Predicted Signalized Intersection Crash Data (Treatment Sites)

\begin{tabular}{|c|c|c|c|c|c|c|}
\hline & \multicolumn{6}{|c|}{ Total Predicted Crashes per Year } \\
\hline & 2008 & 2009 & 2010 & 2011 & 2012 & 2013 \\
\hline Bgr. $/ 31^{\text {st }} \mathrm{S}$ & 32.5 & 28.7 & 22.4 & 34.5 & 34.7 & 36.4 \\
\hline Bgr. $/ 41^{\text {st } S}$ & 39.9 & 35.5 & 29.7 & 40.7 & 40.9 & 43.0 \\
\hline Bgr. $/ 47^{\text {th }} \mathrm{S}$ & 41.0 & 36.6 & 30.3 & 45.2 & 45.6 & 48.5 \\
\hline Bgr. $/ 54^{\text {th }} \mathrm{S}$ & 44.1 & 40.1 & 33.6 & 48.0 & 48.3 & 50.8 \\
\hline Bgr. $/ 62^{\text {nd }} S$ & 44.0 & 39.1 & 32.8 & 44.9 & 45.1 & 47.4 \\
\hline Bgr. $/ 70^{\text {th }} \mathrm{S}$ & 39.0 & 34.7 & 29.8 & 40.7 & 40.9 & 43.0 \\
\hline $\mathrm{RR} / 54^{\text {th }} \mathrm{S}$ & 53.3 & 47.8 & 39.4 & 54.9 & 54.2 & 54.4 \\
\hline $\mathrm{RR} / 62^{\text {nd }} \mathrm{S}$ & 26.8 & 23.9 & 20.0 & 27.5 & 27.7 & 29.1 \\
\hline
\end{tabular}

The EB methodology, as described in the previous section, was applied to the treatment and comparison sites. Equations (3) - (19) were used to calculate all parameters and determine the CMF for $\mathrm{CFI}$ conversion. The results of the EB analysis are given in Table 5.

Table 5: EB Analysis Results

\begin{tabular}{|c|c|}
\hline Parameter & Value \\
\hline$\hat{\pi}$ & 945.08 \\
\hline$V A R\{\hat{\pi}\}$ & 1372.25 \\
\hline$\hat{\lambda}$ & 830 \\
\hline$V A R\{\hat{\lambda}\}$ & 830 \\
\hline$\tilde{\theta}$ & 0.877 \\
\hline$V A R\{\tilde{\theta}\}$ & 0.0021 \\
\hline$\sigma\{\hat{\theta}\}$ & 0.045 \\
\hline$\delta$ & 115.08 \\
\hline$V A R\{\delta\}$ & 2202.25 \\
\hline
\end{tabular}

The crash modification factor for CFI conversion (given as $\theta$ in the table) for the total number of crashes for local conditions is:

$\mathrm{CMF}_{\mathrm{CFI}}=0.877$

It should be noted that this CMF is valid for partial CFIs, since seven out of eight treatment sites were of this type. The Crash Reduction Factor (CRF) in this case is:

$\mathrm{CRF}_{\mathrm{CFI}}=12.3 \% \pm 4.6 \%$

This analysis is based on limited data, so this methodology can be used as the general guidance to repeat the analysis as a part of a future effort.

\section{STUDY LIMITATIONS}

Although this study uses proven methodologies for CMF development, there are some limitations that need to be addressed in follow-up studies. Majority of the recent CFI implementations included only partial conversions, with crossovers on two approaches. Therefore, the findings from this study are valid only for partial CFIs. Limited available data, especially in the after period, provide only crash data for several years. To strengthen the results, more data in the after period are needed. This should be an ongoing effort, since more CFls are being implemented every year. The SPF for signalized intersections needs more calibration for local conditions. One approach might include developing local calibration factors for certain areas using more samples, unlike the factor that was developed here for the entire Salt Lake City area. 
This approach would improve the crash prediction leading to better results. Also, this study considers only the total number of crashes. Future studies need to incorporate different crash types and severities. The finding from future related studies can also lead to better designs for CFI that would improve safety for all users.

\section{CONCLUSIONS}

The CFI is a complex design that displaces the left turns upstream of the main intersection using signalized crossover intersections. The main benefits of a CFI are improved operations attributed to higher capacities, as well as a reduction of conflict points with a potential to improve safety. This design typically requires better guidance and signage to inform drivers about specific maneuvers well ahead of the intersection. Driver expectancy is one of the main problems with this design, since it differs from traditional intersections. It also reduces accessibility in the vicinity of the intersection and is not pedestrianfriendly due to long crosswalks.

The goal of this paper was to develop a CMF for CFI conversions using test cases from Salt Lake City, Utah. For this purpose, the Empirical Bayes method was applied to eight treatment and five comparison sites using six-year crash data. The findings are valid for partial CFI conversions (displaced left turns on two approaches) since seven out of eight sites are of this type. The analysis resulted in a CMF of 0.877 for total crashes for local conditions, meaning that the partial CFI has a potential to reduce total crashes by about $12 \%$.

Currently, little is documented about the safety performance of CFIs in the published literature, mainly because of the limited number of implementations and the lack of data for the after period. Until the conclusion of this paper, there were no studies that reported CMFs for CFI conversions, and the CMF Clearinghouse does not contain any information. Therefore, this study is one of the first to quantify CFI safety and develop CMFs for conversions. The EB methodology presented in this paper can serve as a guideline for future safety studies using different test cases and more crash data.

\section{References}

[1] Innovative Intersections: Overview and Implementation Guidelines. Wilbur Smiths Associates and HDR Thompson. Prepared for Community Planning Association of Southwest Idaho (COMPASS), April 2008.

[2] Wolshon, B. Toolbox on Intersection Safety and Design: Chapter 1 - Geometric Design. Prepared for The Institute of Transportation Engineers and The Federal Highway Administration, February 2004.

[3] Kittelson \& Associates, Inc. Displaced Left Turn Intersection: Informational Guide. Federal Highway
Administration (FHWA), August 2014. https://safety.fhwa.dot.gov/intersection/alter_design/pdf/fh wasa14068_dlt_infoguide.pdf

[4] CMF Clearinghouse, www.cmfclearinghouse.org, accessed August 22, 2018

[5] Highway Safety Manual. American Association of State Highway and Transportation Officials (AASHTO), 2010.

[6] Shultz, G., Thurgood, D. J., Olsen, A.N., Reese, C.S. Transportation Safety Data and Analysis Volume 1: Analyzing the Effectiveness of Safety Measures using Bayesian Methods. UDOT Report No. UT-10.12a, 2010.

[7] Hauer, E., Harwood, D.W., Council, F.M., and Griffith, M.S. Estimating Safety by the Empirical Bayes Method: A Tutorial. Transportation Research Record: Journal of the Transportation Research Board, No. 1784, Transportation Research Board of the National Academies, Washington, D.C., 2002, pp. 126-131.

[8] Bared, J. G., Edara, P. K., and Jagannathan, R. Design and Operational Performance of Double Crossover Intersection and Diverging Diamond Interchange. Transportation Research Record: Journal of the Transportation Research Board, No. 1912, Washington D. C. 2006, pp. 31-38.

[9] Hughes, W., Jagannathan, R., Sengupta, D., and Hummer, J. Alternative Intersections/Interchanges: Informational Report (AIIR). FHWA-HRT-09-06, FHWA, U.S. Department of Transportation, 2010.

[10] Carroll, D., and Lahusen, D. Operational Effects of Continuous Flow Intersection Geometrics A Deterministic Model. Transportation Research Record: Journal of the Transportation Research Board, No. 2348, Transportation Research Board of the National Academies, Washington, D.C., 2013, pp. 1-11.

[11] You, X., Li, L., and Ma, W. Coordinated Optimization Model for Signal Timings of Full Continuous Flow Intersections. Transportation Research Record: Journal of the Transportation Research Board, No. 2356, Transportation Research Board of the National Academies, Washington, D.C., 2013, pp. 23-33.

[12] Zhao, J., Ma, W., Head, K. L., and Yang, X. Optimal operation of displaced left-turn intersections: A lane-based approach. Transportation Research Part C: Emerging Technologies, Vol. 61, 2015, pp. 29-48.

[13] Bedini, A., Zhang, L., and Garoni, T. M. A Case Study of a Continuous Flow Intersection and Its Impact on Public Transit. IEEE $20^{\text {th }}$ International Conference on Intelligent Transportation Systems (ITSC), 2017.

[14] Shams, A. Traffic Operations Assessment: Comparison of Traditional Improvement Solutions and Connected Autonomous Vehicle Traffic Control Algorithms. Master's Thesis, University of Wyoming, August 2018.

[15] Park, S. and Rakha, H. Continuous Flow Intersections: A Safety and Environmental Perspective. 13th International IEEE Annual Conference on Intelligent Transportation Systems, Portugal, September 2010.

[16] Porter, R.J. Empirical Bayes Methodology. CVEEN 7520 Transportation Safety course, University of Utah, 2011. Class notes. 